\title{
Renal Excretion of Fluoride in Renal Failure and after Renal Transplantation
}

\author{
V. PARSONS, A. A. CHOUDHURY, J. A. H. WASS, A. VERNON
}

British Medical fournal, 1975, 1, 128-130

\section{Summary}

We have compared the renal excretion of fluoride in a variety of patients with chronic renal failure maintained with and without protein restriction before and during regular dialysis treatment and after transplantation.

The patients tended to continue to excrete normal dietary loads of fluoride quite well until renal function was seriously reduced. From a regression of function on excretion the mean level of creatinine clearance when a normal dietary load of fluoride $0.0526 \pm 0.019 \mathrm{mmol} / 2 £ \mathrm{~h}$ $(1.0 \pm 0.36 \mathrm{mg} / 24 \mathrm{~h})$ has a $90 \%$ chance of being excreted lies aroun $16 \mathrm{ml} / \mathrm{min}$, a level when most patinsst with renal failure will be symptomatic. Acute loading of such patients with additional fluoride in the form of sodium fluoride from $40 \mathrm{mg}$ to $60 \mathrm{mg} /$ day showed a twofold to threefold increase of serum fluoride concentrations, slight increases in urinary fluoride excretion, and heavy tissue absorption, suggesting that prior fluoride loading of the skeleton had not taken place. These effects contrasted with those in patients with normal renal function and with those in one patient with skeletal saturation due to prolonged loading.

After renal transplantation fluoride excretion increased but reached normal levels within three months of satisfactory function, suggesting that fluoride loading in renal failure and during regular dialysis therapy had not been excessive.

\section{Introduction}

Considerable discussion has ranged on the issue of whether the addition of fluoride to water supplies used in cooking, drinking, and dialysis would add an appreciable burden of fluoride to the body and whether this burden could account for some of the toxic features of chronic renal failure (Kaye et al., 1960; Siddiqui et al., 1970; Posen, 1971). Raised concentrations of fluoride have been found in the plasma and bone of patients with renal failure (Taves et al., 1965; Taves et al., 1968; Kim et al., 1970; Fournier et al., 1971; Parsons et al., 1971.) As normal people absorb fluoride easily it seemed important to determine at what level of renal function fluoride excretion failed to match absorption. The fluoride ion has been shown to cross the dialysis membrane freely (Taves, 1968; Prosser et al., 1970) so in patients on regular dialysis treatment fluoride from dialysis fluid might collect in the blood to be excreted. After transplantation homoeostatic mechanisms for the excretion of fluoride should come into play and reduce the plasma level, then fluoride excretion might reflect the degree of tissue loading, particularly of bone, whose turnover might be increased during the recovery of normal renal function. We therefore studied a series of patients who had undergone renal transplantation.

\footnotetext{
King's College Hospital Renal Unit, Dulwich Hospital, London

V. PARSONS, D.M., F.R.C.P., Physician

A. A. CHOUDHURY, M.B., M.R.C.P., Registrar

J. A. H. WASS, M.B., M.R.C.P., Registrar

A. VERNON, M.A., Research Assistant
}

To test the concept of skeletal fluoride saturation in renal failure known quantities of sodium fluoride were given to patients with renal failure under balance conditions and the retention over short periods was followed. Patients were informed of the nature of the study and their consent and that of an ethical committee was obtained.

\section{Methods}

Before regular dialysis treatment, patients were maintained on either a free diet or a restricted protein diet. Blood was obtained for biochemical measurements, and 24-hour urine collections ( 8 a.m. to 8 a.m.) were made for similar estimations of electrolytes, fluoride, and creatinine so that the excretion of fluoride could be correlated with simple creatinine clearances and excretion of other ions. Urine and plasma were prepared with suitable buffers for the measurement of fluoride ion activity using the ion specific electrode method (Fry and Taves, 1970; Tusl, 1972).

Most of the patients came from south east London and Kent or Leeds, where no fluoride is added to the water. A group of patients with no evidence of renal failure who were being investigated for other purposes had their 24-hour urinary fluoride excretion measured also. They acted as a control group, and most came from the same parts of south east London and Kent as the patients; they excreted just under $0.0526 \mathrm{mmol}(1 \mathrm{mg})$ of fluoride a day (mean \pm S.D., $0.0505 \pm 0.0316 \mathrm{mmol} / 24 \mathrm{~h}(0.96 \pm 0.6$ $\mathrm{mg} / 24 \mathrm{~h})$ ). Several transplant patients were followed for some months until their clearances had stabilized using a protocol already described for our transplant group (Ellis et al., 1972). The patients with stable renal failure and those with normal renal function were maintained on a known diet to which was added $20 \mathrm{mg}$ and then $40 \mathrm{mg}$ of sodium fluoride a day for five-day periods after a preliminary five-day period without supplements. Plasma fluoride levels were measured when the patients were on sodium fluoride supplements, and faeces were ashed, diffused, and the fluoride measured (Stuart, 1970).

\section{Results}

The plot of the daily urinary fluoride excretion against creatinine clearance is shown in fig. 1 expressed as a logarithmic function to the base 2 . The regression equation shows a correlation of $\mathbf{r}=$ 0.6 despite the scatter related to a non-uniformity of intake and type of renal disease. Taking the standard error of this regression, the point where it becomes increasingly unlikely for a normal excretion of fluoride $(0.0526 \pm$ (S.E.) $0.019 \mathrm{mmol}(1.0 \pm 0.36$ $\mathrm{mg}$ ) fluoride in 24 hours) lies around $16 \mathrm{ml} / \mathrm{min}$. The ranges of urinary excretion of fluoride among patients with normal renal function are shown in fig. 2 together with those of patients who had undergone transplantation at different intervals from the first week to three months after adequate restoration of function. After transplantation fluoride output increased and then reached the normal range within two months of satisfactory renal function (fig. 3). Follow-up of these patients for several months suggested that their excretion remained slightly above normal for a long time. The plots show a steady parallel between sodium excretion and fluoride when compared with calcium and phosphate, which steadily increased as dietary increases matched and exceeded bone utilization. The results of limited fluoride balance studies on the patients with renal failure and one patient who 


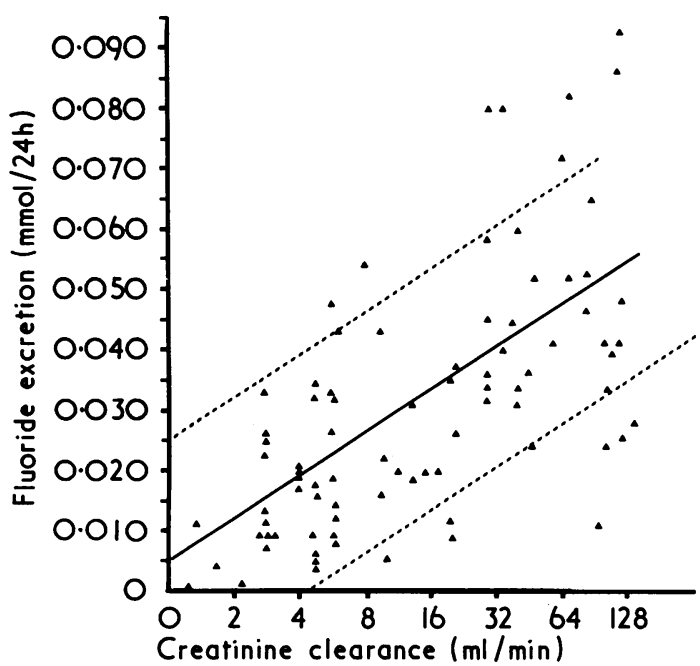

FIG. 1-Urinary fluoride excretion plotted against creatinine clearance on log scale, $y=0.0077 x+0.12 ; r=0.6$ standard error of regression \pm $0.19 \mathrm{mg}$.

Conversion: SI to Traditional Units-Fluoride $1 \mathrm{mmol}=19 \mathrm{mg}$.

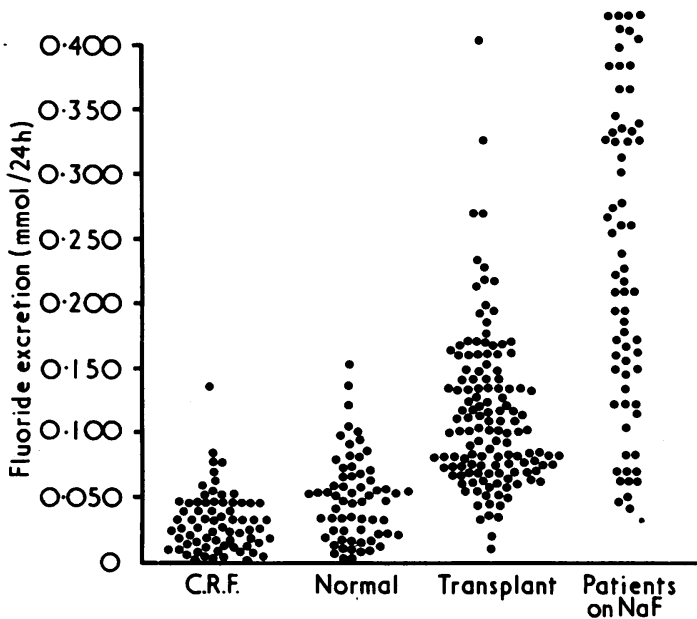

FIG. 2-Fluoride excretion in patients with chronic renal failure (C.R.F.) some of whom were receiving low-protein diet; normal patients; transplant patients after restitution of normal renal function; and patients on sodiumfluoride therapy with calcium supplements and vitamin $\mathrm{D}$ for osteoporosis. Conversion: SI to Traditional Units-Fluoride: $1 \mathrm{mmol}=19 \mathrm{mg}$.

had been on fluoride for 18 months for possible therapeutic effect on her multiple myelomatosis (Cohen et al., 1969) are shown in the table. This patient with multiple myelomatosis (case 6) was the only one "in balance," and she increased her output to retain only a mean of $30 \%$ of the ingested load, providing a valuable check on our methods. The rise in plasma fluoride when these supplements were given to patients with chronic renal failure is shown in fig. 4.

\section{Discussion}

Absorbed fluoride is quickly distributed through body fluid spaces as shown by ${ }^{18} \mathrm{~F}$ studies (Carlson et al., 1960). The availability of fluoride in water and food depends on the complexes the ion forms with other minerals (Brudevold et al., 1972; Ericsson et al., 1972; O'Dell et al., 1973) and with protein complexes (Spencer et al., $1970 \mathrm{a}$; Zipkin et al., 1970). The concentrations of total fluoride in plasma are low and are regulated by two mechanisms-skeletal sequestration and urinary excretion (Yeh et al., 1970). Most inorganic fluoride available for absorption is excreted in the urine. Our data from the patients without renal failure suggest that a normal person living in our area does not absorb much more than $0.078 \mathrm{mmol}(1.5 \mathrm{mg})$ of fluoride a day, a finding in keeping with those in similar groups in the U.S.A. (Sanfillipo

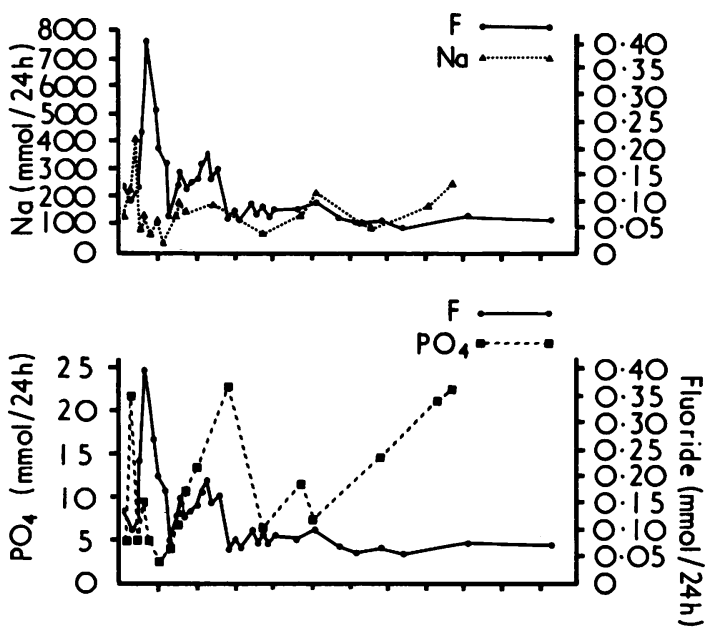
of fluoride in bone but whether saturation has been reached is difficult to estimate. The equilibrium between intake and plasma concentration on the one hand and the bone on the other is reached without excessive deposition in the latter, however; the maintaining of higher plasma concentrations ensures that the urine excreted contains sufficient fluoride to maintain a balance. A survey of the patients' urinary volumes suggested that, if anything, patients with increasing renal failure tended to excrete larger volumes of urine, reflecting an increased fluid intake of non-fluoridated water. There was no evidence of an increased intake of tea, which might increase fluoride intake. Stressing patients with renal failure with a large load of fluoride resulted in increases in urinary excretion, but fluoride continued to be absorbed into bone as faecal excretion was low, suggesting that in renal failure there is a large available "surface" for acute 
fluoride loading (see table). Studies of animals with normal renal function given ${ }^{18} \mathrm{~F}$ (Wootton, 1974) suggest that bone clears fluoride so effectively that ${ }^{18} \mathrm{~F}$ could be used as a measure of bone blood flow. On dialysis the ion is freely mobile and can cross the Cuprophan membrane in either direction, and so long as the fluoride concentration in the plasma exceeds that of the dialysate the patient will loose fluoride on dialysis.

Balance Data showing Dietary Intake and Output (Faeces and Urine) for Three Five-day Periods. Three Patients (Cases 1-3) had Advanced Renal Failure, Two (Cases 4 and 5) had Moderate Reduction in Renal Function, and One (Case 6) had had NaF as Treatment for Myelomatosis, with Moderate Reduction in Renal Function

\begin{tabular}{|c|c|c|c|c|}
\hline Case No. & $\begin{array}{l}\text { Mean Fluoride } \\
\text { Intake (mmoi) } \\
\text { in 5-day } \\
\text { Periods }\end{array}$ & $\begin{array}{c}\text { Mean Fluoride } \\
\text { Output (mmol) } \\
\text { in 5-day } \\
\text { Periods }\end{array}$ & $\begin{array}{c}\text { Percentage } \\
\text { Retained by } \\
\text { Patient }\end{array}$ & $\begin{array}{l}\text { Blood Fluoride } \\
\text { Concentration } \\
(\mu \mathrm{mol} / 1)\end{array}$ \\
\hline 1 & $\begin{array}{l}0 \cdot 26 \\
5 \cdot 5 \\
8 \cdot 7\end{array}$ & $\begin{array}{l}0 \cdot 27 \\
0 \cdot 79 \\
0 \cdot 22\end{array}$ & $\begin{array}{r}3 \\
86 \\
98\end{array}$ & $\begin{array}{l}12 \cdot 6 \\
17 \cdot 4 \\
16 \cdot 3\end{array}$ \\
\hline 2 & $\begin{array}{l}0.26 \\
5 \cdot 5 \\
10 \cdot 8\end{array}$ & $\begin{array}{l}0 \cdot 24 \\
0 \cdot 16 \\
0 \cdot 23\end{array}$ & $\begin{array}{r}8 \\
97 \\
98\end{array}$ & $\begin{array}{r}6 \cdot 3 \\
12 \cdot 6 \\
11 \cdot 1\end{array}$ \\
\hline 3 & $\begin{array}{c}0.26 \\
5 \cdot 5 \\
10 \cdot 9\end{array}$ & $\begin{array}{l}0.12 \\
0.13 \\
0.35\end{array}$ & $\begin{array}{l}54 \\
98 \\
97\end{array}$ & $\begin{array}{l}12 \cdot 6 \\
20 \cdot 0 \\
36 \cdot 3\end{array}$ \\
\hline 4 & $\begin{array}{c}0.79 \\
5.5 \\
10.8\end{array}$ & $\begin{array}{l}0.90 \\
1.11 \\
1.90\end{array}$ & $\begin{array}{r}-14 \\
80 \\
82\end{array}$ & $\begin{array}{r}6 \cdot 8 \\
8 \cdot 9 \\
12 \cdot 6\end{array}$ \\
\hline 5 & $\begin{array}{c}0.53 \\
5.5 \\
10.8\end{array}$ & $\begin{array}{l}0.69 \\
1 \cdot 23 \\
3 \cdot 78\end{array}$ & $\begin{array}{l}30 \\
78 \\
65\end{array}$ & $\begin{array}{r}8.9 \\
12.6\end{array}$ \\
\hline 6 & $\begin{array}{r}5 \cdot 5 \\
5 \cdot 5 \\
10 \cdot 8\end{array}$ & $\begin{array}{l}4.99 \\
6.79 \\
6.02\end{array}$ & $\begin{array}{r}10 \\
-\quad 23 \\
44\end{array}$ & $\begin{array}{l}11 \cdot 1 \\
16 \cdot 8 \\
19 \cdot 5\end{array}$ \\
\hline
\end{tabular}

Conversion: Sl to Traditional Units
Fluoride: 1 mol $=19 \mathrm{~g}$.

The question remains that if the patient with severe renal failure has difficulty in excreting the normal dietary and fluid load of fluoride presented to him can this slight but steady load of fluoride in bone add to the renal bone disease commonly seen in dialysis patients? Fluoride in bone tissue probably affects the structure and composition of bone in various ways, few of which have been proved in man, but suggestive results are available from animal work, and fluoride could affect bone by $(a)$ direct action on enzymatic activity; this includes alterations in bone resorptive pathways, mainly inhibitory (Goldhaber, 1967; Lukert et al., 1972), the inhibition of citrate metabolism (Hac and Freeman, 1969), the turnover of bone lipids (Dirksen, 1972), the synthesis of citric acid cycle inhibitors (Peters et al., 1969), and effects on ribonuclease (Chang, 1970); (b) the induction of hormonal effects, chiefly secondary hyperparathyroidism owing to a failure of bone resorption to maintain a satisfactory concentration of ionized calcium at the parathyroid gland surface (Faccini, 1969); or (c) direct physical effects of the substitution of hydroxyl radicals within hydroxyapatite to form fluorapatite (Young et al., 1969).

There is mounting evidence that increased bone formation can occur in patients with normal renal function given fluoride if at the same time additional calcium and vitamin $\mathrm{D}$ are given to the patient so that some of the factors under $(a)$ and $(b)$ above can be reversed to produce more mineralized bone (Jowsey et al., 1972).

Histological examination of fluorotic bone suggests that these combined factors lead to an increase in osteoid, signs of hyperparathyroid bone disease, and increased disorganized bone formation with subperiosteal outgrowth resulting in a basically weakened, if slightly increased, volume of bone, the weakening to some extent depending on calcium loading during fluoride administration (Beary, 1969).

It was suggested that bone containing high fluoride concentrations showed histological evidence of more severe renal osteodystrophy, but this was not the case in our limited study (Parsons et al., 1971). It could be suggested, however, that the more severe the bone disease the more likely is fluoride to collect at the bone surface. If one of the major features of prolonged dialysis bone disease is osteoporosis as well as other features of osteomalacia and hyperparathyroidism the presence of fluoride might not be entirely deleterious, especially if high calcium and appropriate vitamin D therapy are maintained (Oreopoulos et al., 1973).

In studies where subjects with adequate renal function were given an increased intake of fluoride up to $1.11 \mathrm{mmol} /$ day $(21$ $\mathrm{mg} /$ day) absorption remained high and though urinary fluoride excretion increased all the patients went into positive balance (Spencer et al., $1970 \mathrm{~b}$ ). When the fluoride supplements were reduced and further balance studies performed the extra load of fluoride was not excreted rapidly, suggesting that fluoride is firmly incorporated into bone and not discharged quickly. This finding fits our data from transplanted patients well as the excretion of fluoride fell rapidly with the restoration of renal function, suggesting that most of the extra load of fluoride sequestered in bone is released very slowly and may be an index of bone turnover after transplantation. The concept is supported by the finding of slightly yet persistently raised serum fluoride concentration in the transplanted patient with good renal function (Johnson and Taves, 1974).

This work was supported by the Medical Research Council with grants to A.A.C. and A.V. We thank Mrs. C. Davies and Miss Mary Herns, supported by the King's College Hospital research committee, for technical help. We are indebted to the patients and staff of the wards for their care in the collection of specimens. We are thankful to $\mathrm{Mr}$. M. Bewick for all the surgery involved in the group of transplanted patients.

\section{References}

Beary, D. F. (1969). The Anatomical Record, 164, 305.

Brudevold, F., Moreno, E. and, Bakhos, Y. (1972). Archives of Oral Biology, 17,1155 .

Carlson, C. H., Armstrong, W. D., and Singer, L. (1960). Proceedings of the Society for Experimental Biology and Medicine, 104, 235.

Chang, C. W. (1970). Canadian fournal of Biochemistry and Physiology, 48, 450 .

Cohen, P., Nichols, G. L., and Banks, H. H. (1969). Clinical Orthopaedics, 64, 221 .

Dirksen, T. R. (1972). Archives of Oral Biology, 17, 55.

Ellis, F. G., et al. (1972). Guy's Hospital Reports, 121, 7 .

Ericsson, Y., Helstrom, I., and Hofvander, Y. (1972). Acta Paediatrica, $61,459$.

Faccini, J. M. (1969). Calcified Tissue Research, 3, 1.

Fournier, A. E., et al. (1971). Fournal of Clinical Investigation, 50, 592

Fry, B. W., and Taves, D. R. (1970). Fournal of Laboratory and Clinical Medicine, 75, 1020.

Goldhaber, P. (1967). Israel fournal of Medical Sciences, 3, 617.

Hac, L. R., and Freeman, S. (1969). Proceedings of the Society of Experimental Biology and Medicine, 130, 428.

Johnson, W. J. \& Taves, D. R. (1974). Kidney International, 5, 451.

Jowsey, J., et al. (1972). American fournal of Medicine, 53, 43.

Kaye, M., et al. (1960). Medicine, 39, 157.

Kim, D., et al. (1970). Transactions. American Society for Artificial Internal

Organs, 16, 474.
Lukert, B. P., Bolinger, R. E., and Meek, J. C. (1972). Fournal of Clinical Endocrinology and Metabolism, 35, 387 .

O'Dell, B. L., Moroni, R. I., and Regan, W. O. (1973). Fournal of Nutrition, 103, 841.

Oreopoulos, D. G., et al. (1973). Abstracta Xth Congress of the European Dialysis and Transplant Association, 173.

Parsons, V., et al. (1971). Proceedings of the European Dialysis and Transplant Association, 8, 139.

Peters, R. A., Shorthouse, M. and Ward, P. F. V. (1969). Biochemical fournal, 113, 9.

Posen, G. A., Marier, J. R., and Jaworski, F. (1971). Fluoride, Quarterly Reports, 4, 114

Prosser, D. I., et al. (1970). Proceedings of the European Dialysis and Transplant Association, 7, 103.

San Filippo, F. A., and Battistone, G. C. (1971). Clinica Chimica Acta, $31,453$.

Siddiqui, J. Y., et al. (1970). Proceedings of the European Dialysis and Transplant Association, 7,110

Spencer, H., et al. (1970 a). Fournal of Nutrition, 100, 1415

Spencer, H., et al. (1970 a). Fournal of Nutrition, 100, 1415.

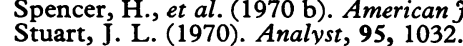

Taves, D. R., et al. (1965). Archives of Internal Medicine, 115, 167. Taves, D. R., et al. (1965). Archives of Internal Medicine, 115, 167.
Taves, D. R., et al. (1968). Transactions. American Society for Artificial
Internal Organs, 14, 412.

Tusl, J. (1972). Analytical Chemistry, 44, 1693.

Wootton, R. (1974). Clinical Science and Molecular Medicine, 47, 73.

Yeh, M. C., Singer, L., and Armstrong, W. D. (1970). Proceedings of the Society of Experimental Biology and Medicine, 135, 421.

Young, R. A., Van Der Lugt, W., and Elliott, J. C. (1969). Nature, 223, 729

Zipkin, I., Zucas, S. M., and Stillings, B. R. (1970). Fournal of Nutrition, 100, 293. 